\title{
THE MODEL OF GAS DISCHARGE SUSTAINED BY THE QUADRUPOLE ELECTROMAGNETIC WAVE IN WAVEGUIDE STRUCTURE WITH VARYING RADIUS OF METAL ENCLOSURE
}

\author{
N.A. Azarenkov, V.P. Olefir, A.E. Sporov \\ V.N. Karazin Kharkiv National University, Kharkiv, Ukraine \\ E-mail: vpolefir@karazin.ua,sporov@karazin.ua
}

This article presents the results of the theoretical study of stationary state of gas discharge sustained by the electromagnetic wave with azimuth wavenumber $m=-2$ in three component magnetized plasma-metal waveguide structure of slightly varying radius of metal enclosure in the framework of electromagnetic model. It was studied the influence of the external magnetic field value, the electron effective collision frequency and other parameters on the phase characteristics, spatial attenuation, discharge stability and axial plasma density profile in the structure with constant radius of metal waveguide and with radius that varies slightly along the discharge.

PACS: 52.35-g, 52.50.Dg

\section{INTRODUCTION}

The modern technologies require plasma sources with large length, large volume or with large area of operating surface. The defining characteristics of plasma sources that used in different technological processes are the fact that plasma density value and plasma density uniformity in axial, radial and azimuth directions are determined by the type of a wave sustaining the discharge, by the external magnetic field value, by the geometrical sizes of plasma column and waveguide structure, and also by the efficiency of energy transmission from wave to plasma.

In order to obtain discharge plasma with the desired characteristics the analytical and numerical modeling of plasma parameters axial distribution in the discharge sustained by electromagnetic wave with different azimuth wavenumber values are carried out. The electrodynamic approach is widely used for such modeling [1] In the framework of such approach plasma is described by the simplified equations and the main attention is paid to the description of the wave that sustains the discharge. Such approach can be used to model stationary state of gas discharges that are sustained by the electromagnetic waves of the surface type. In the paper [1] were declared that the waves with azimuth wavenumber $m= \pm 2$ are perspective for plasma column sustaining. The waveguides with varying outer metal wall along the discharge structure can be used for improving the axial plasma density uniformity [2]. This paper is devoted to the studying of the influence of variable radius of metal waveguides on the properties of the discharge that is sustained by the electromagnetic wave with $m=-2$.

\section{BASIC EQUATIONS}

It is considered the electrodynamic model of gas discharge in diffusion controlled regime sustained by the electromagnetic wave with azimuth wave number $m=-2$ that propagates along the three component waveguide structure. This structure consists of magnetized plasma column of radius $R_{P l}$ that is separated by the vacuum slab from the metal waveguide wall of radius $R$ that varies along the axial direction. External steady magnetic field $\vec{B}_{0}=\left(0,0, B_{0}\right)$ is directed along the axis of the discharge structure. Plasma is considered as cold and weakly absorbing media [3] that is characterized by the effective electron collision frequency $v$. This frequency is considered to be small as compared with the wave frequency $\omega$ and constant in axial and radial directions. Plasma density is considered to be uniform in the radial direction and slightly varying in the axial direction on the distances of wavelength order. In this case it can be assumed that the wave field change slightly along the discharge and the solutions of the system of Maxwell equations that govern electromagnetic wave propagation can be found in WKB approach:

$$
E, B_{r, \varphi, z}(r, \varphi, z)=E, B_{r, \varphi, z}(r, z) \mathrm{e}^{-i \omega t+i m \varphi+\int_{z_{0}}^{z} k_{3}\left(z^{\prime}\right) d z^{\prime}}
$$

where $m$ and $k_{3}$ are azimuth and axial wavenumber, $E, B$ - amplitude of electric and magnetic wave fields, respectively. Changing the $A$ value along the discharge at the distances of the wavelength order is small compared to the magnitude of this quantity $\left(A^{-1}(\partial A / \partial z) \ll k_{3}\right)$, where symbol $A$ denotes $E, B$, $k_{3}, n$ or $R$. So, all terms of order $O\left(k_{3}^{-1}(\partial \ln (A) / \partial z)\right)$ are neglected in further expressions [4].

In the considered case the axial wave components in plasma region can be expressed as:

$E_{z}^{p l}(r)=\sum_{s=1}^{2} C_{s} I_{m}\left(k_{s} r\right), B_{z}^{p l}(r)=\frac{i \varepsilon_{1}}{\varepsilon_{2} k k_{3}} \sum_{s=1}^{2} C_{s} F_{s} I_{m}\left(k_{s} r\right)$

where $F_{s}=\varepsilon_{3}\left(k_{3}^{2}-k^{2} \varepsilon_{1}\right) \varepsilon^{-1}-k_{s}^{2}, \quad k_{s}^{2}=p_{1} \pm \sqrt{p_{1}^{2}-p_{2}}$, $p_{1}=\left[\left(\varepsilon_{1}+\varepsilon_{3}\right)\left(k_{3}^{2}-k^{2} \varepsilon_{1}\right)+k^{2} \varepsilon_{2}^{2}\right]\left(2 \varepsilon_{1}\right)^{-1}$,

$p_{2}=\varepsilon_{3}\left[\left(k_{3}^{2}-k^{2} \varepsilon_{1}\right)^{2}-k^{4} \varepsilon_{2}^{2}\right], \quad I_{m}-$ modified Bessel function of the first kind and $C_{s}$ - field constants. The expressions for the components of collision plasma permittivity tensor $\varepsilon_{1,2,3}$ are written in the usual form [3]. It is necessary to mention that the obtained expressions are valid where $k_{1} \neq k_{2}$. Otherwise it is necessary or to solve the system of Maxwell equation numerically, or to use different kind of solutions (2) at this point.

Other wave field components in the plasma region can be written as: 


$$
\left\{\begin{array}{l}
E_{r}^{p l}=-\frac{i}{k_{3}} \sum_{s=1}^{2} \frac{k^{2} \varepsilon_{3}+k_{s}^{2}}{k_{s}} C_{s} I_{m}^{\prime}\left(k_{s} r\right)+i \frac{m}{r} \frac{\varepsilon_{1}}{k_{3} \varepsilon_{2}} \sum_{s=1}^{2} \frac{F_{s}}{k_{s}^{2}} C_{s} I_{m}\left(k_{s} r\right) \\
E_{\varphi}^{p l}=-\frac{\varepsilon_{1}}{k_{3} \varepsilon_{2}} \sum_{s=1}^{2} \frac{F_{s}}{k_{s}} C_{s} I_{m}^{\prime}\left(k_{s} r\right)+\frac{m}{r} \frac{1}{k_{3}} \sum_{s=1}^{2} \frac{k^{2} \varepsilon_{3}+k_{s}^{2}}{k_{s}^{2}} C_{s} I_{m}\left(k_{s} r\right), \\
B_{r}^{p l}=\frac{\varepsilon_{1}}{k \varepsilon_{2}} \sum_{s=1}^{2} \frac{F_{s}}{k_{s}} C_{s} I_{m}^{\prime}\left(k_{s} r\right)-\frac{m}{r} k \varepsilon_{3} \sum_{s=1}^{2} \frac{C_{s}}{k_{s}^{2}} I_{m}\left(k_{s} r\right) \\
B_{\varphi}^{p l}=-i k \varepsilon_{3} \sum_{s=1}^{2} \frac{C_{s}}{k_{s}} I_{m}^{\prime}\left(k_{s} r\right)+i \frac{m}{r} \frac{\varepsilon_{1}}{k} \sum_{\varepsilon_{2}}^{2} \frac{F_{s}}{k_{s}^{2}} C_{s} I_{m}\left(k_{s} r\right)
\end{array}\right.
$$

where stroke denotes the derivative with respect to argument.

The wave axial components in vacuum region, which satisfy the boundary conditions on the waveguide metal wall, can be written as:

$$
E_{z}^{V}(r)=A G(\psi r), H_{z}^{V}(r)=B Q(\psi r),
$$

where $\psi^{2}=k_{3}^{2}-k^{2}, A$ and $B$ - field constants, and functions $G(\psi r)$ and $Q(\psi r)$ have the following form:

$$
\left\{\begin{array}{l}
G(\psi r)=\frac{K_{m}(\psi r)}{K_{m}(\psi R)}-\frac{I_{m}(\psi r)}{I_{m}(\psi R)} \\
Q(\psi r)=\frac{K_{m}(\psi r)}{K_{m}^{\prime}(\psi R)}-\frac{I_{m}(\psi r)}{I_{m}^{\prime}(\psi R)}
\end{array},\right.
$$

where $K_{m}-$ modified Bessel functions of the second kind. Other wave field components in vacuum region can be written as:

$$
\left\{\begin{array}{l}
E_{r}^{V}=\frac{1}{\psi^{2}}\left\{k \frac{m}{r} B Q(\psi r)-i \psi k_{3} A G(\psi r)\right\}, \\
E_{\varphi}^{V}=\frac{1}{\psi^{2}}\left\{k_{3} \frac{m}{r} A G(\psi r)+i \psi k B Q^{\prime}(\psi r)\right\}, \\
B_{r}^{V}=-\frac{1}{\psi^{2}}\left\{k \frac{m}{r} A G(\psi r)+i \psi k_{3} B Q^{\prime}(\psi r)\right\}, \\
B_{\varphi}^{V}=\frac{1}{\psi^{2}}\left\{k_{3} \frac{m}{r} B Q(\psi r)-i \psi k A G^{\prime}(\psi r)\right\} .
\end{array}\right.
$$

Taking into account the continuity of tangential wave field components at the plasma-vacuum interface it is possible to obtain the dispersion equation in the following form:

$$
\frac{\left(Z_{1}-Y_{1}+e_{1}\right)\left(Z_{2}-\varepsilon_{3} Y_{2}+h_{2}\right)}{\left(Z_{1}-Y_{2}+e_{2}\right)\left(Z_{2}-\varepsilon_{3} Y_{1}+h_{1}\right)}=\frac{F_{2}}{F_{1}},
$$

where

$$
Z_{1}=\frac{k}{\psi} \frac{Q^{\prime}\left(\psi R_{P l}\right)}{Q\left(\psi R_{P l}\right)}, \quad Z_{2}=\frac{k}{\psi} \frac{G^{\prime}\left(\psi R_{P l}\right)}{G\left(\psi R_{P l}\right)},
$$

$e_{s}=\frac{m}{R_{P l}} \frac{k^{3} \varepsilon_{2}}{\varepsilon_{1} F_{s}}\left[\frac{\varepsilon_{3}}{k_{s}^{2}}-\frac{1}{\psi^{2}}\right], \quad h_{s}=\frac{m}{R_{P l}} \frac{\varepsilon_{1}}{k \varepsilon_{2}} F_{s}\left[\frac{1}{k_{s}^{2}}-\frac{1}{\psi^{2}}\right]$, $Y_{s}=\frac{k}{k_{s}} \frac{I_{m}^{\prime}\left(k_{s} R_{P l}\right)}{I_{m}\left(k_{s} R_{P l}\right)}$. The constants $C_{s}, A, B$ can be written as:

$$
\begin{aligned}
& A=\frac{E_{z}\left(r=R_{P l}\right)}{G\left(\psi R_{P L}\right)}, B=i \frac{\varepsilon_{1}}{\varepsilon_{2} k k_{3}} \sum_{s=1}^{2} F_{s} C_{s} \frac{I_{m}\left(k_{s} R_{P l}\right)}{Q\left(\psi R_{P l}\right)}, \\
& C_{1}=-\frac{Z_{2}-\varepsilon_{3} Y_{2}+h_{2}}{\varepsilon_{3}\left[Y_{2}-Y_{1}\right]-\left[h_{2}-h_{1}\right]} \frac{E_{z}\left(r=R_{P l}\right)}{I_{m}\left(k_{1} R_{P l}\right)}, \\
& C_{2}=\frac{Z_{2}-\varepsilon_{3} Y_{1}+h_{1}}{\varepsilon_{3}\left[Y_{2}-Y_{1}\right]-\left[h_{2}-h_{1}\right]} \frac{E_{z}\left(r=R_{P l}\right)}{I_{m}\left(k_{2} R_{P l}\right)} .
\end{aligned}
$$

The expression of the axial wave energy flux component can be written as:

$$
\begin{aligned}
S_{z}= & \frac{c}{4} \operatorname{Re}\left(\int_{0}^{R_{P l}}\left(E_{r}^{p l^{*}} B_{\varphi}^{p l}-E_{\varphi}^{p l^{*}} B_{r}^{p l}\right) r d r+\right. \\
& \left.+\int_{R_{P l}}^{R}\left(E_{r}^{V^{*}} B_{\varphi}^{V}-E_{\varphi}^{V^{*}} B_{r}^{V}\right) r d r\right),
\end{aligned}
$$

where asterisk denotes the complex conjugate.

Let us express the energy that is absorbed per unit length of the discharge and consumed to excitation, ionization, heating of the neutral gas in the following form:

$$
Q=i \frac{\omega}{8}\left(\varepsilon_{j i}^{*}-\varepsilon_{i j}\right) \int_{0}^{R_{P I}} E_{i}^{*} E_{j} r d r
$$

The equations (9) and (10) give the possibility to write the equation of wave energy balance along the discharge in the next form [1]:

$$
\frac{d S_{z}(z)}{d z}+Q=0
$$

The $S_{z}(z)$ has the sense of such wave energy flux that is necessary for sustaining of plasma column from coordinate $z$ up to the end of the discharge. The end of the discharge in the stable region is determined as axial coordinate where $S_{z}=0$.

The electrodynamic model must contain one more equation that connects the wave power absorbed per unit length of discharge $Q$ with local plasma density $n_{0}$. This next equation must be determined by the kinetics of the discharge but can be written in the simplified model form as [1]:

$$
Q=Q_{\beta} N^{1+\beta},
$$

where $N=\omega_{P e}^{2} \omega^{-2}-$ dimensionless plasma density, $Q_{\beta}$ - constant that does not depend on axial coordinate. The parameter $\beta$ is determined by the regime of the discharge. For the case of free fall or diffusion regime $\beta=0[1]$.

It is necessary to mention that the wave can sustain the discharge in free-fall/diffusion regimes in those regions on the phase diagrams where the Zakrzewski's stability criterion is fulfilled [1]:

$$
\frac{\partial}{\partial n} \frac{\left(\operatorname{Im}\left(k_{3}\right)\right)}{n}<0
$$

So, it is possible the situation, when the end of discharge is determined not at the point, when $S_{z}=0$, but at the beginning of the region, where the Zakrzewski's stability criterion (13) is not fulfilled.

\section{MAIN RESULTS}

The electromagnetic wave that sustains the discharge is the eigenwave of discharge structure on the whole length of the plasma column. The possibility of axial plasma source parameters variation is mainly determined by dispersion properties of the wave sustaining the discharge. Such circumstances determined the detailed investigation of the phase and attenuation properties of the non-symmetric $(m=-2)$ electromagnetic waves, that can be used for discharge sustaining.

The calculations were carried out for the fixed values of the external magnetic field $\Omega=\omega_{c e} \omega^{-1}=0.2$ and dimensionless radius of plasma column $\sigma=\omega R_{P l} c^{-1}=0.5$. The 
results of the dispersion equation (7) investigation are presented on the Figs. 1, 2.

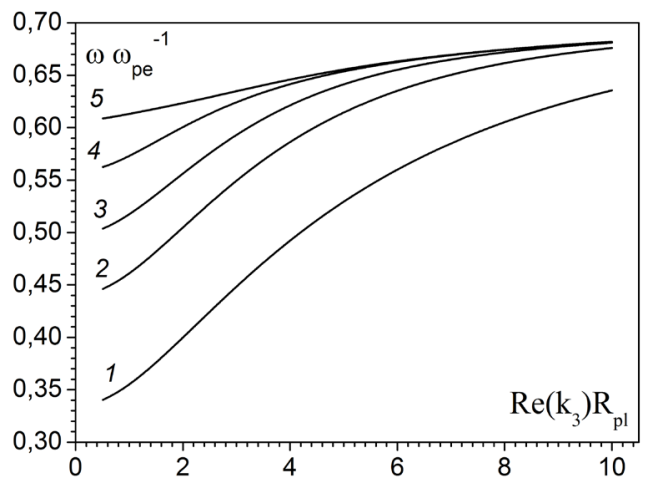

Fig. 1. Wave dispersion properties for $\Omega=0.2, \sigma=0.5$, $v \omega^{-1}=10^{-5}$. Curves marked

by the numbers $1-5$ correspond to the $\eta=R R_{P l}^{-1}$

parameter value: $1.1,1.2,1.3,1.5$, and 2.0

The influence of vacuum slab thickness on the dispersion properties of the wave with $m=-2$ are presented on Fig. 1. In the case of rather small external magnetic fields $(\Omega<1)$ the decrease of the vacuum gap thickness leads to the deceleration of the wave. The changing of $R$ strongly influences wave dispersion in the region of small axial wave numbers. When waveguide metal wall radius grows up to $\eta \geq 2$ its influence on the wave dispersion properties becomes practically negligible.

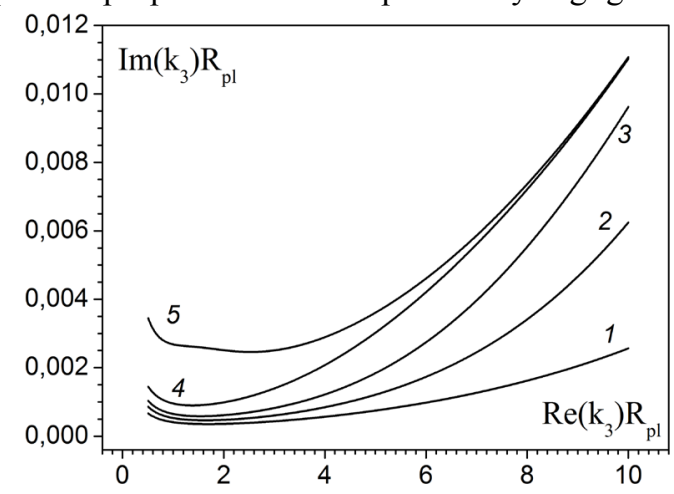

Fig. 2. Attenuation properties of the wave.

Parameters and the numbering of the curves are the same as in Fig. 1

The study shows the existence of the minimum value of spatial attenuation coefficient in the region where $\operatorname{Re}\left(k_{3}\right) R_{\mathrm{pl}} \approx 1$. With the growing of vacuum gap thickness the value of coefficient $\alpha=\operatorname{Im}\left(k_{3}\right) R_{\mathrm{pl}}$ increases and shifts towards the region of shorter wavelengths.

The phase and attenuation properties wave with $m=-2$ substantially depend on the external magnetic field value (Fig. 3). While the magnetic field increases the $\omega \omega_{p e}^{-1}$ decreases in the region of small $x=\operatorname{Re}\left(k_{3}\right) R_{\mathrm{pl}}$ values and increases for large $x$ values.

The magnetic field increasing results in a decrease of the coefficient $\alpha$ in the whole axial wavenumbers region (Fig. 4).

The dependence of wave attenuation coefficient $\alpha$ for some values of $v \omega^{-1}$ parameter is shown in the Fig. 5. The intensification of collisions leads to the increase of the wave attenuation coefficient in the range of small axial wavenumbers and especially in the range of large axial wave numbers. This can leads to the decrease of the region where the stable discharge can exist (according to the criterion (12)).

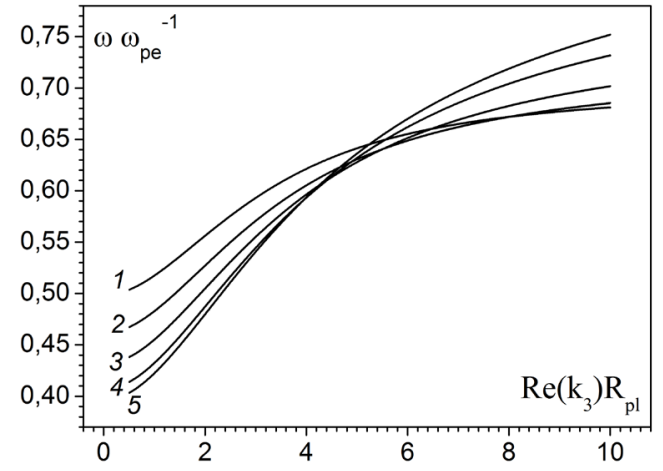

Fig. 3. Wave dispersion properties for $\eta=1.3$,

$$
\sigma=0.5, v \omega^{-1}=10^{-5} \text {. Curves marked }
$$

by the numbers $1-5$ correspond to the $\Omega$ parameter value $0.2,0.4,0.6,0.8$, and 0.9

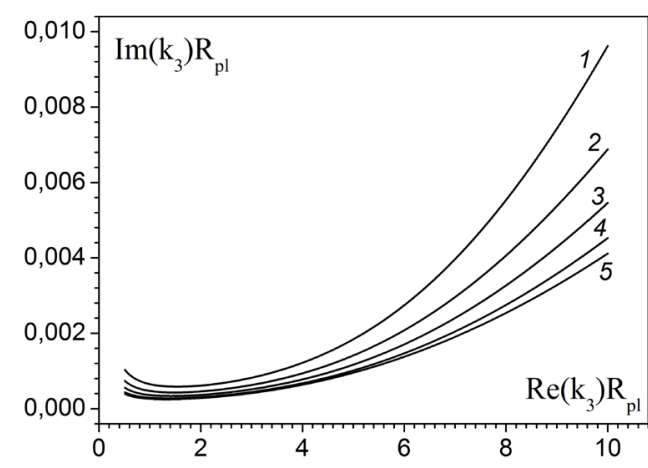

Fig. 4. Attenuation properties of the wave. Parameters and the numbering of the curves are the same as in Fig. 3

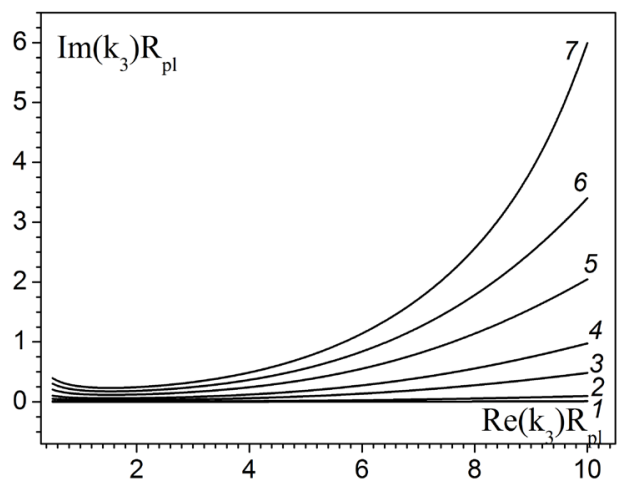

Fig. 5. Attenuation properties of the wave for $\Omega=0.2$, $\sigma=0.5, \eta=1.3$. Curves marked by the numbers $1-7$ correspond to the $v \omega^{-1}$ value $: 10^{-5} ; 10^{-4} ; 5 \cdot 10^{-4} ; 5 \cdot 10^{-3}$;

$$
2 \cdot 10^{-3} ; 3 \cdot 10^{-3} ; 4 \cdot 10^{-3}
$$

The wave that sustains the discharge is the eigen wave of the waveguide system on the whole length of the discharge. So, with the help of obtained phase properties one can estimate maximum possible plasma density of the discharge. It is shown, that maximum possible density values (determined by the $\omega \omega_{p e}^{-1}$ parameter) for discharges sustained by the $m=-2$ wave in smaller than for discharges sustained by the symmetric and dipolar waves [5].

To study the axial plasma density distribution in the 
discharge (in the parameter $N=\omega_{p e}^{2} \omega^{-2}$ wave frequency is fixed) it was introduced the dimensionless axial coordinate $\xi=v z /\left(\omega R_{p l}\right) \quad(z-$ axial coordinate that is measured from the generator up to the end of discharge). The discharge length $L$ is the $\xi$ value where the total wave energy flux in plasma and vacuum become equal to zero or the Zakrzewski's stability criterion (13) is not fulfilled.
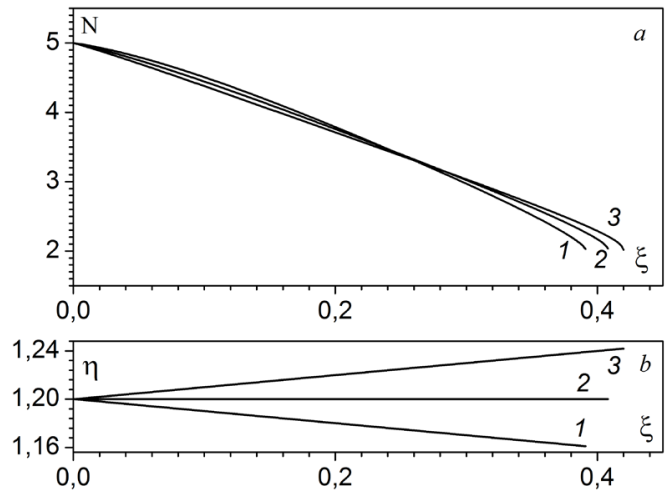

Fig. 6. The axial structure (a) and the laws of dimensionless waveguide radius $\eta$ variation along

the discharge (b) for $\sigma=0.5, \Omega=0.2, \eta=1.2$

Axial plasma density $N$ distribution along the plasma column is represented on Fig. 6. It is necessary to point that during the calculation of the plasma density profile, the condition of discharge stability (13) was checked. It were studied the linearly decreased (line 1), steady (line 2) and linearly increased (line 3) $\eta$ profiles. The study has shown that slightly varying metal enclosure influences the discharge length similarly to the dipolar mode [5]. But for the quadrupole mode $m=-2$ the variation of $R$ make influence on the plasma density axial profile also at the beginning of the discharge (see Fig. 6).

\section{CONCLUSIONS}

It was studied the influence of slightly varying radius of metal enclosure on the axial structure of the discharge sustained by non-symmetric mode with $m=-2$. It was shown that variable radius of the waveguide of metal enclosure make influence on the discharge on $m=-2$ mode similarly as for discharges on the dipolar mode [5] except the influence on the discharge profile at the beginning of the discharge.

\section{REFERENCES}

1. M. Moisan, J. Hubert, J. Margot, and Z. Zakrzewski. The Development and Use of Surface-Wave Sustained Discharges for Applications // in Advanced Technologies Based on Wave and Beam Generated Plasmas. 1999 / Ed. by H. Schlüter, A. Shivarova, (Kluwer Academic Publisher, Amsterdam), p. 1-42.

2. J. Wolinska-Szatkowska. Surface wave discharge in a conical tube// J. of Phys. D: Appl. Phys. 1987, v. 20, p. 977-978.

3. A.I. Akhiezer, I.A. Akhiezer, R.V. Polovin, A.G. Sitenko, K.N. Stepanov. Electrodynamics of Plasma. M.: "Science", 1974.

4. G.G. Lister, T.R. Robinson. Strongly damped surface waves in plasmas. I. The WKB approximation // J. Phys. D: Appl. Phys. 1991, v. 24, p. 1993-1999.

5. N.A. Azarenkov, V.P. Olefir, A.E. Sporov. Electromagnetic model of gas discharge in long tube of slightly varying radius // Problems of Atomic Science and Technology. Series "Plasma Physics". 2018, № 6, p. 113-116.

Article received 04.06.2019

\title{
МОДЕЛЬ ГАЗОВОГО РАЗРЯДА, ПОДДЕРЖИВАЕМОГО КВАДРУПОЛЬНОЙ ЭЛЕКТРОМАГНИТНОЙ ВОЛНОЙ В ВОЛНОВОДНОЙ СТРУКТУРЕ С ПЕРЕМЕННЫМ РАДИУСОМ МЕТАЛЛИЧЕСКОЙ СТЕНКИ
}

\author{
Н.А. Азаренков, В.П. Олефир, А.Е. Споров
}

Представлены результаты теоретического исследования в рамках электромагнитной модели стационарного газового разряда, поддерживаемого электромагнитной волной с азимутальным волновым числом $m=-2$ в трехкомпонентной магнитоактивной плазменно-металлической волноводной структуре со слабо изменяющимся вдоль разряда радиусом металлического кожуха. Изучено влияние внешнего магнитного поля, эффективной частоты столкновений электронов и других параметров на фазовые характеристики, пространственное затухание, стабильность разряда и аксиальный профиль плотности плазмы в структуре с постоянным радиусом металлического волновода и слабо изменяющимся вдоль разряда.

\section{МОДЕЛЬ ГАЗОВОГО РОЗРЯДУ, ЩО ПІДТРИМУСТЬСЯ КВАДРУПОЛЬНОЮ ЕЛЕКТРОМАГНІТНОЮ ХВИЛЕЮ У ХВИЛЕВОДНІЙ СТРУКТУРІ ЗІ ЗМІННИМ РАДІУСОМ МЕТАЛЕВОЇ СТІНКИ}

\section{М.О. Азарснков, В.П. Олефір, О.С. Споров}

Представлено результати теоретичного дослідження в рамках електромагнітної моделі стаціонарного газового розряду, що підтримується електромагнітною хвилею з азимутальним хвильовим числом $m=-2$ у трикомпонентній магнітоактивній плазмово-металевій хвилеводній структурі з радіусом металевого кожуху, що слабко змінюється вздовж розряду. Вивчено вплив зовнішнього магнітного поля, ефективної частоти зіткнень електронів та інших параметрів на фазові характеристики, просторове загасання, стабільність розряду та аксіальний профіль густини плазми в структурі з незмінним радіусом металевого хвилеводу та 3 таким, що слабко змінюється уздовж розряду. 